\title{
PENGARUH PERCEIVED USEFULNESS, PERCEIVED EASE OF USE, DAN KUALITAS LAYANAN TERHADAP KEPUASAN UNTUK MEMBANGUN LOYALITAS
}

\author{
Ida Ayu Cynthia Saisaria Mandasari ${ }^{1}$ \\ I Gusti Ayu Ketut Giantari ${ }^{2}$
}

\author{
${ }^{1,2}$ Fakultas Ekonomi dan Bisnis Universitas Udayana, Bali, Indonesia \\ e-mail: cynthiasaisariamandasari@yahoo.com
}

\begin{abstract}
ABSTRAK
Penelitian ini bertujuan untuk mengetahui pengaruh perceived usefulness, perceived ease of use, dan kualitas layanan terhadap kepuasan pengguna untuk membangun loyalitas pengguna aplikasi GO-JEK di Kota Denpasar. Sampel yang digunakan sebanyak 170 orang pengguna yang sudah pernah menggunakan aplikasi layanan GO-JEK minimal 3 kali dalam 3 bulan terakhir yang berdomisili di Kota Denpasar dengan teknik nonprobability sampling. Penelitian ini menggunakan teknik analisis PLS (Partial Least Square). Hasil penelitian menemukan bahwa perceived usefulness, dan perceived ease of use memiliki pengaruh positif dan signifikan terhadap kepuasan pengguna, perceived ease of use memiliki pengaruh positif dan signifikan terhadap perceived usefulness, kualitas layanan memiliki pengaruh positif tetapi tidak signifikan terhadap kepuasan pengguna, kualitas layanan memiliki pengaruh positif dan signifikan terhadap loyalitas. Selanjutnya, kepuasan pengguna memiliki pengaruh positif dan signifikan terhadap loyalitas.
\end{abstract}

Kata Kunci: perceived usefulness, perceived ease of use, kualitas layanan, kepuasan pengguna, loyalitas.

\begin{abstract}
This study aims to determine the effect of perceived usefulness, perceived ease of use, and quality of service to user satisfaction to build user loyalty GO-JEK applications in the city of Denpasar. The sample used as many as 170 users who have been using the service application GO-JEK at least 3 times in the last 3 months who live in Denpasar with nonprobability sampling technique. This research uses analysis technique PLS (Partial Least Square). The results of the study found that perceived usefulness, and perceived ease of use have a positive and significant effect on user satisfaction, perceived ease of use has a positive and significant effect on perceived usefulness, service quality has a positive but insignificant effect on user satisfaction, service quality has influence Positive and significant to loyalty. Furthermore, user satisfaction has a positive and significant influence on loyalty.
\end{abstract}

Keywords: perceived usefulness, perceived ease of use, service quality, user satisfaction, loyalty 


\section{PENDAHULUAN}

Perkembangan teknologi telekomunikasi yang sangat pesat ternyata membawa dampak yang besar bagi segala aspek, tidak terkecuali perkembangan di dunia bisnis dan pemasaran. Pebisnis saat ini berlomba menciptakan aplikasi mobile pada smartphone yang akan memberikan kemudahan bagi penggunanya untuk merasakan produk maupun jasa yang ditawarkan oleh perusahaan. Salah satunya adalah aplikasi bisnis dibidang jasa layanan antar secara online. Dengan hanya menggunakan aplikasi yang disediakan perusahaan pada smartphone, para konsumen tidak perlu lagi membuang-buang waktu dan tenaganya untuk keluar rumah, maupun keluar dari tempat bekerja seperti untuk mencari transportasi ke pangkalannya, membeli suatu produk, mengantar barang maupun membutuhkan jasa layanan lainnya.

Usaha dalam bidang jasa layanan antar baik layanan antar dalam hal transportasi umum, jasa layanan antar suatu barang maupun dalam membantu membeli suatu barang saat ini pun menjadi prospek usaha yang menguntungkan terutama di daerah Ibu kota dan sekitarnya, masyarakat membutuhkan jasa layanan antar yang praktis dan juga cepat. merek ojek online berhasil merebut pasar, salah satunya adalah GO-JEK. GO-JEK adalah sebuah perusahaan teknologi berjiwa sosial yang bertujuan untuk meningkatkan kesejahteraan pekerja di berbagai sektor informal di Indonesia. GO-JEK bermitra dengan sekitar 200.000 pengendara ojek yang berpengalaman dan terpercaya di Indonesia, untuk menyediakan berbagai macam layanan. 
Kegiatan GO-JEK bertumpu pada tiga nilai pokok yakni kecepatan, inovasi, dan dampak sosial. Sistem aplikasi GO-JEK sangat bergantung pada tiga hal, yaitu sistem, teknologi, dan sumber daya manusia. Sebagai perusahaan baru, upaya agar sistem dan teknologi aplikasi GO-JEK dapat diterima dengan baik oleh penggunanya, maka perilaku menolak perlu diubah atau sistem perlu dipersiapkan terlebih dahulu agar pemakainya mau berperilaku menerima. Penerimaan pengguna terhadap sistem informasi dapat diukur dengan beberapa model penerimaan yang dikembangkan saat ini.

Ada banyak model penerimaan yang digunakan untuk mengukur penerimaan sebuah sistem informasi. Salah satu model yang digunakan untuk mengukur penerimaan adalah Technology Acceptance Model (TAM). Technology Acceptance Model (TAM) merupakan model yang populer digunakan untuk mengukur adopsi teknologi informasi mengenai penggunaan maupun penerimaan sistem informasi (Dalbouh, 2013). Model Technology Acceptance Model (TAM), pengguna cenderung menggunakan sebuah sistem teknologi apabila sistem tersebut mudah digunakan dan bermanfaat baginya. Kim dan Hyung (2014) menegaskan bahwa kegunaan dan kemudahan penggunaan secara signifikan mempengaruhi sikap terhadap penggunaan sistem informasi.

Penelitian ini memodifikasi Technology Acceptance Model (TAM), dengan menggunakan penerimaan pemakai teknologi ditentukan oleh dua variabel kunci yang diusulkan oleh Davis (1989) yaitu persepsi kemanfaatan (perceived usefulness) dan persepsi kemudahan penggunaan (perceived ease of use). Persepsi kemanfaatan (perceived usefulness) adalah tingkat kepercayaan individu 
bahwa penggunaan teknologi akan meningkatkan kinerjanya, dan persepsi kemudahan penggunaan (perceived ease of use) adalah tingkat kepercayaan individu bahwa penggunaan teknologi membuatnya lebih mudah untuk menyelesaikan pekerjaan.

Zao dan Cao (2012) menunjukkan bahwa kepuasan pengguna langsung dipengaruhi oleh perceived usefulness dan niat pengguna untuk terus menggunakannya. Penelitian lain yang dilakukan oleh Tananjaya (2012) pun menunjukkan keputusan pengguna untuk menerima sebuah software akuntansi diindikasikan oleh tingkat kepuasan penggunaan software tersebut yang dipengaruhi oleh kemudahan dalam penggunaannya (perceived ease of use). Hasil penelitian serupa pun ditunjukkan oleh beberapa peneliti Amin et al. (2014), Kim dan Hyung (2014), Tananjaya (2012), Budiman dan Arza (2013), George dan Kumar (2013) dan Liebanas-Cabanillas et al. (2013).

Selain berhubungan dengan kepuasan, dengan kemudahan yang diberikan oleh suatu sistem, maka pengguna akan merasakan manfaat yang lebih sehingga persepsi kemudahan memiliki hubungan terhadap persepsi kemanfaatan. Writz et al. (2016), mengungkapkan bahwa perceived ease of use mempengaruhi perceived usefulness dalam hal mengapa konsumen membeli merek tertentu. Cho (2015) menyatakan perceived ease of use mempengaruhi perceived usefulness pelanggan pada online store. Hasil serupa dinyatakan oleh Rusdi et al. (2016), bahwa secara teoritis persepsi kemudahan penggunaan (perceived ease of use) berpengaruh siginifikan terhadap persepsi kegunaan (perceived usefulness). 
Faktor sumber daya manusia memberi kontribusi yang sangat besar pada sistem aplikasi GO-JEK, maka faktor ini sangat sulit ditiru oleh pesaing. Salah satunya memberikan kualitas layanan yang baik. Agyapong (2011) menyatakan dimensi kualitas layanan seperti tangibility, kehandalan, responsiveness, assurance, dan empati secara signifikan mempengaruhi sikap pelanggan dalam hal mendapatkan kepuasan.

Tjiptono (2011) pun mengungkapkan bahwa kualitas layanan jasa merupakan upaya pemenuhan kebutuhan dan keinginan konsumen serta ketepatan penyampaiannya dalam mengimbangi harapan konsumen. Hasil penelitian serupa dikemukakan oleh Ravichandran et al. (2010) dimana peningkatan kualitas pelayanan dapat memuaskan dan mengembangkan kepuasan pelanggan yang akhirnya mempertahankan pelanggan dihargai.

GO-JEK sebagai teknologi layanan jasa transportasi dan berbagai jasa layanan yang baru diciptakan, semakin marak beredar dan penggunaannya semakin diminati oleh masyarakat di Kota Denpasar terutama pada layanan GORIDE dan GO-FOOD yang sudah ada sejak pertama aplikasi GO-JEK diciptakan.

Berdasarkan latar belakang yang telah dikemukakan di atas maka masalah yang akan dirumuskan dalam penelitian ini adalah:

1) Bagaimanakah pegaruh perceived usefulness terhadap kepuasan pengguna GO-JEK di Kota Denpasar?

2) Bagaimanakah pegaruh perceived ease of use terhadap kepuasan pengguna GO-JEK di Kota Denpasar? 
3) Bagaimanakah pegaruh perceived ease of use terhadap perceived usefulness pengguna GO-JEK di Kota Denpasar?

4) Bagaimanakah pegaruh kualitas layanan terhadap kepuasan pengguna GO-JEK di Kota Denpasar?

5) Bagaimanakah pegaruh kualitas layanan terhadap loyalitas pengguna GO-JEK di Kota Denpasar?

6) Bagaimanakah pegaruh kepuasan pengguna terhadap loyalitas pengguna GO-JEK di Kota Denpasar?

\section{METODE PENELITIAN}

\section{Jenis dan Sumber Data}

Dalam penelitian ini, yang menjadi data kuantitatif adalah usia responden dan usia penggunaan layanan aplikasi GO-JEK. Dalam penelitian ini, yang menjadi data kualitatif adalah data pribadi yang terdiri dari jenis kelamin, pendidikan, dan jawaban serta pendapat responden.

Data primer adalah data yang diperoleh dari responden langsung yaitu pengguna GO-JEK yang sudah pernah menggunakan aplikasi dan layanan jasa GO-JEK. Data sekunder adalah data yang diperoleh atau dikumpulkan dari berbagai sumber seperti buku, artikel, jurnal ilmiah serta situs-situs resmi untuk menunjang proses penelitian.

\section{Variabel Penelitian}


Variabel bebas (exogen) dalam penelitian ini adalah perceived usefulness (X1), percieved ease of use (X2), kualitas layanan (X3). Variabel terikat (endogen) dalam penelitian ini adalah kepuasan pengguna (Y1), loyalitas (Y2).

\section{Populasi dan Sampel}

Populasi dalam penelitian ini adalah seluruh pengguna aplikasi layanan GO-JEK terutama pengguna layanan GO-RIDE dan GO-FOOD yang berdomisili di Kota Denpasar, maka jumlah populasi tidak bisa dihitung jumlahnya (infinate population). Jumlah atau ukuran sampel yang dipilih dalam penelitian ini adalah: Jumlah sampel $=$ Jumlah indikator x 5. Maka, $34 \times 5=170$.

\section{Metode Penentuan Sampel}

Teknik pengambilan sampel yang digunakan dalam penelitian ini adalah teknik nonprobability sampling. Adapun pertimbangan sampel yang digunakan dalam penelitian ini , yatiu:

1) Pernah mengakses dan menggunakan layanan aplikasi GO-JEK minimal 3 kali dalam 3 bulan terakhir terutama layanan GO-RIDE \& GO-FOOD dengan pertimbangan tingginya kedua layanan ini diminati.

2) Berdomisili di Kota Denpasar.

3) Berusia minimal 18 tahun atau telah menyelesaikan pendidikan sekolah menengah atas.

\section{Metode Pengumpulan Data}


Metode pengumpulan data kuesioner disebarkan secara langsung kepada responden untuk diisi sendiri atau ditanyakan melalui wawancara. Selanjutnya kuesioner akan diukur dengan menggunakan skala Likert. Skala Likert digunakan untuk mengukur sikap, pendapat, dan tanggapan seseorang mengenai perceived usefulness, perceived ease of use, dan kualitas layanan terhadap kepuasan yang akan berdampak pada loyalitas pengguna aplikasi GO-JEK.

\section{Teknik Analisis Data}

Penelitian ini menggunakan uji validitas dan reliabilitas untuk menguji hasil kuesioner dan menggunakan teknik analisis SEM (Structural EquationModelling) berbasis component atau variance yaitu PLS (Partial Least Square). Pendekatan PLS adalah distribution free, tidak mengasumsikan data berdistribusi tertentu, dapat berupa nominal, kategori, ordinal, interval, dan rasio. PLS digunakan untuk mengetahui kompleksitas hubungan antar variabel laten dan indikator-indikatornya. Adapun Langkah-langkah PLS adalah :

1) Merancang model struktural (inner model)

2) Merancang model pengukuran (outer model)

3) Mengkontruksi diagram jalur (path diagram)

4) Konversi diagram jalur ke sistem persamaan

5) Estimasi

6) Evaluasi goodness of fit

7) Pengujian hipotesis 


\section{HASIL DAN PEMBAHASAN}

\section{Karakteristik Responden}

Karakteristik responden penelitian digambarkan dengan menyajikan karakteristiknya berdasarkan variabel demografi yaitu jenis kelamin, usia, masa kerja dan pendidikan terakhir. Berdasarkan Tabel 1. menunjukkan responden berjenis kelamin laki-laki sebanyak 61 orang $(35,9 \%)$ dan berjenis kelamin perempuan sebanyak 109 orang (64,1\%). Dilihat dari tingkat usia menunjukkan responden berusia 18-24 tahun sebanyak 111 ornag (65,3\%), usia 25-39 tahun sebanyak 46 orang $(27,1)$, tidak terdapat responden usia 40-50 tahun dan $>50$ tahun sebanyak 13 orang $(7,6 \%)$. Berdasarkan pendidikan terakhir responden menunjukkan responden dengan pendidikan terakhir SMA sebanyak 17 orang (10\%), D1, D2, D3 atau sederajat sebanyak 12 orang $(7,1 \%)$, Sarjana (S1) sebanyak 128 orang (75,3\%), S2 sebanyak 9 orang (5,3\%), dan SMK sebanyak 4 orang $(2,4 \%)$.Sedangkan dilihat dari pekerjaannya menunjukkan bahwa responden bekerja sebagai PNS sebanyak 15 orang $(8,8 \%)$, pegawai swasta sebanyak 80 orang $(47,1)$, wiraswasta sebanyak 40 orang $(23,5 \%)$, belum bekerja sebanyak 17 orang $(10 \%)$, ibu rumah tangga sebanyak 16 orang $(9,4 \%)$, dan dokter sebanyak 2 orang $(1,2 \%)$.

Tabel 1.

Karakteristik Responden

\begin{tabular}{|c|c|c|c|c|}
\hline No & Variabel & Klasifikasi & Jumlah (orang) & Persentase \\
\hline 1 & Jenis Kelamin & $\begin{array}{l}\text { Laki-laki } \\
\text { Perempuan }\end{array}$ & $\begin{array}{c}61 \\
109\end{array}$ & $\begin{array}{l}35,9 \\
64,1\end{array}$ \\
\hline \multicolumn{3}{|c|}{ Jumlah } & 170 & 100 \\
\hline
\end{tabular}




\begin{tabular}{|c|c|c|c|c|}
\hline \multirow{4}{*}{2} & & 18-24 tahun & 111 & 65,3 \\
\hline & & 25-39 tahun & 46 & 27,1 \\
\hline & Tingkat Usia & 40-50 tahun & 0 & 0 \\
\hline & & $>50$ tahun & 13 & 7,6 \\
\hline \multirow{6}{*}{3} & & Jumlah & 170 & 100 \\
\hline & & SMA & 17 & 10 \\
\hline & & $\begin{array}{l}\text { D1, D2, D3 atau sederajat } \\
\text { Sariana (S1) }\end{array}$ & 12 & 7,1 \\
\hline & Pendidikan & $\mathrm{S} 2$ & 128 & 75, \\
\hline & & SMK & 9 & 5,3 \\
\hline & & & 4 & 2,4 \\
\hline \multirow{8}{*}{4} & \multirow{8}{*}{ Pekerjaan } & Jumlah & 170 & 100 \\
\hline & & PNS & 15 & 8,8 \\
\hline & & Pegawai Swasta & 80 & 47 , \\
\hline & & Wiraswasta & 40 & 23,5 \\
\hline & & Belum bekerja & 17 & 10 \\
\hline & & Ibu Rumah Tangga & 16 & 9,4 \\
\hline & & Dokter & 2 & 1,2 \\
\hline & & Jumlah & 170 & 100 \\
\hline
\end{tabular}

\section{Hasil Uji Validitas dan Reliabilitas}

Tabel 2.

Hasil Uji Validitas dan Reliabilitas

\begin{tabular}{|c|c|c|c|c|c|}
\hline Faktor & Variabel & $\begin{array}{c}\text { Koefisien } \\
\text { Korelasi }\end{array}$ & $\begin{array}{c}\text { Keteranga } \\
\text { n }\end{array}$ & $\begin{array}{c}\text { Cronbach } \\
\text { Alpha }\end{array}$ & $\begin{array}{c}\text { Keteranga } \\
\mathbf{n}\end{array}$ \\
\hline & $\begin{array}{l}\text { Menjadikan } \\
\text { pekerjaan lebih } \\
\text { mudah }(\mathrm{X} 1.1)\end{array}$ & 0,884 & Valid & & \\
\hline & $\begin{array}{l}\text { Bermanfaat } \\
(\text { Usefull) (X1.2) }\end{array}$ & 0,889 & Valid & & \\
\hline $\begin{array}{l}\text { Perceived } \\
\text { Usefulness }\end{array}$ & $\begin{array}{l}\text { Mempertinggi } \\
\text { efektivitas } \\
\text { (enhance } \\
\text { efectivness) } \\
\text { (X1.4) }\end{array}$ & 0,895 & Valid & 0,938 & Reliabel \\
\hline & $\begin{array}{l}\text { mengembangka } \\
\mathrm{n} \text { kinerja } \\
\text { pekerjaan } \\
\text { (improve job } \\
\text { performance) } \\
\text { (X1.5) }\end{array}$ & 0,879 & Valid & & \\
\hline & $\begin{array}{l}\text { Adanya } \\
\text { kemudahan } \\
\text { dipelajari } \\
\text { (X2.1) }\end{array}$ & 0,881 & Valid & & \\
\hline \multirow[t]{2}{*}{$\begin{array}{c}\text { Perceived Ease of } \\
\text { Use }\end{array}$} & $\begin{array}{l}\text { Mudah } \\
\text { dipahami dan } \\
\text { dimengerti } \\
\text { (X2.2) }\end{array}$ & 0,904 & Valid & 0,926 & Reliabel \\
\hline & $\begin{array}{l}\text { Mudah untuk } \\
\text { berinteraksi } \\
\text { (X2.3) }\end{array}$ & 0,751 & Valid & & \\
\hline
\end{tabular}




\begin{tabular}{|c|c|c|c|c|c|}
\hline & $\begin{array}{l}\text { Mudah untuk } \\
\text { digunakan/ } \\
\text { dioperasikan. } \\
\text { (X2.4) }\end{array}$ & 0,907 & Valid & & \\
\hline & $\begin{array}{l}\text { Keseluruhan } \\
\text { mudah } \\
\text { digunakan. } \\
(\mathrm{X} 2.5)\end{array}$ & 0,938 & Valid & & \\
\hline & $\begin{array}{l}\text { Kondisi } \\
\text { kendaraan } \\
(\mathrm{X} 3.1 .1)\end{array}$ & 0,942 & Valid & & \\
\hline & $\begin{array}{l}\text { Perlengkapan } \\
\text { keamanan } \\
(\mathrm{X} 3.1 .2)\end{array}$ & 0,926 & Valid & 0,917 & Realiabel \\
\hline & $\begin{array}{l}\text { Identitas driver } \\
\text { (X3.1.3) }\end{array}$ & 0,845 & Valid & & \\
\hline & $\begin{array}{l}\text { Penampilan } \\
\text { driver (X3.1.4) }\end{array}$ & 0,867 & Valid & & \\
\hline & $\begin{array}{l}\text { Keandalan } \\
\text { driver tertib } \\
\text { berlalu lintas } \\
(\mathrm{X} 3.2 .1)\end{array}$ & 0,813 & Valid & & \\
\hline Kualitas Layanan & $\begin{array}{l}\text { Keandalan } \\
\text { driver memesan } \\
\text { makanan di } \\
\text { berbagai } \\
\text { restoran }\end{array}$ & 0,877 & Valid & & \\
\hline & $\begin{array}{l}(\mathrm{X} 3.2 .2) \\
\text { Keandalan } \\
\text { driver }\end{array}$ & & & 0,907 & Reliabel \\
\hline & $\begin{array}{l}\text { memberikan } \\
\text { tarif yang } \\
\text { sesuai (X3.2.3) }\end{array}$ & 0,937 & Valid & & \\
\hline & $\begin{array}{l}\text { Keandalan } \\
\text { driver } \\
\text { memberikan } \\
\text { pelayanan } \\
\text { 24jam. (X3.2.4) }\end{array}$ & 0,912 & Valid & & \\
\hline & $\begin{array}{l}\text { Respon cepat } \\
\text { driver terhadap } \\
\text { pemesanan } \\
(\mathrm{X} 3.3 .1)\end{array}$ & 0,803 & Valid & & \\
\hline & $\begin{array}{l}\text { Respon driver } \\
\text { yang segera } \\
\text { datang setelah } \\
\text { pemesanan }\end{array}$ & 0,781 & Valid & 0,743 & Reliabel \\
\hline Kualitas Layanan & $(\mathrm{X} 3.3 .2)$ & & & & \\
\hline & $\begin{array}{l}\text { Respon driver } \\
\text { dan staff } \\
\text { terhadap } \\
\text { keluhan } \\
\text { (X3.3.3) }\end{array}$ & 0,861 & Valid & & \\
\hline & $\begin{array}{l}\text { Driver terampil } \\
\text { mengemudi } \\
(\mathrm{X} 3.4 .1)\end{array}$ & 0,960 & Valid & 0,957 & Reliabel \\
\hline
\end{tabular}




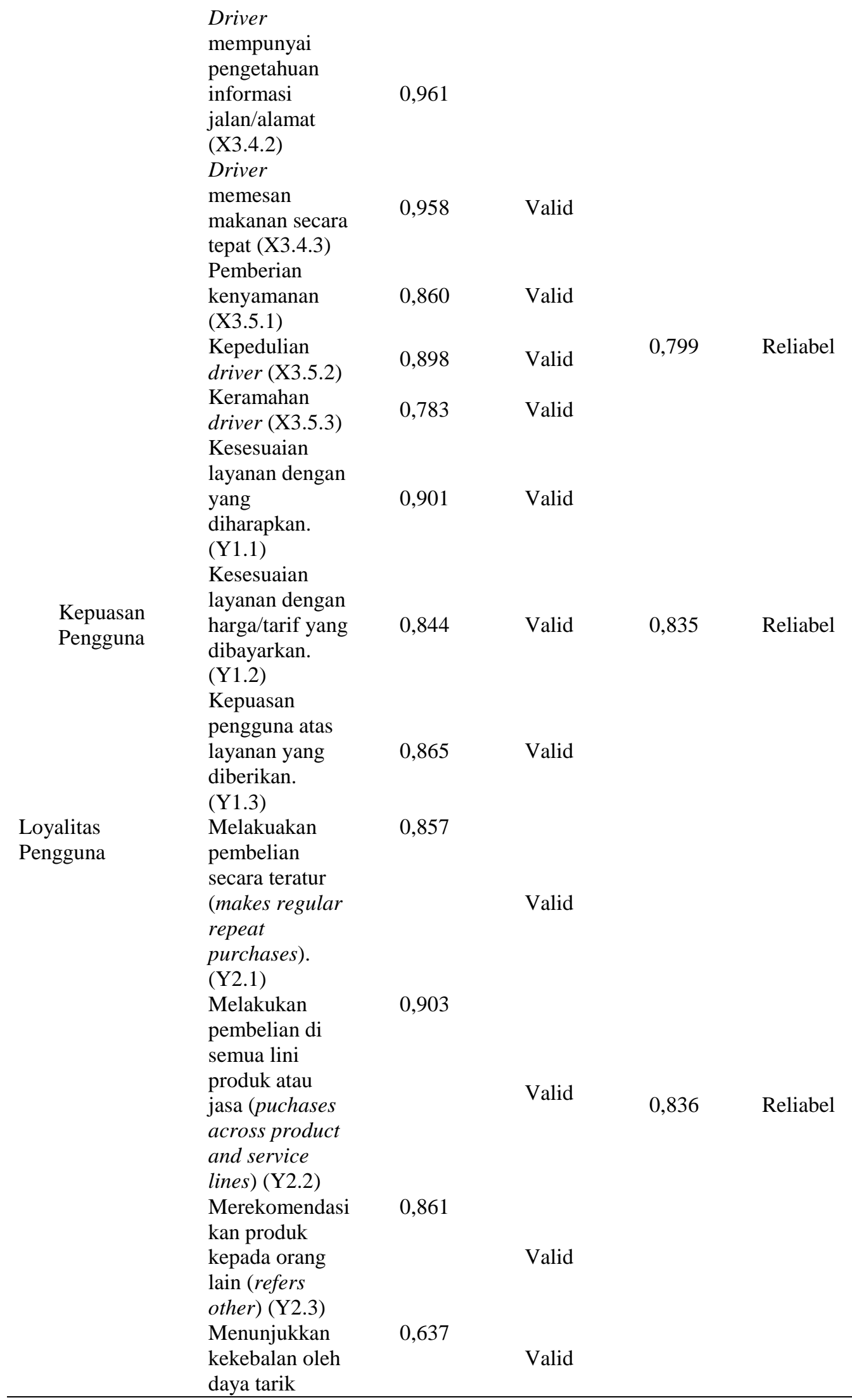


produk sejenis

dari pesaing

(demonstrates

on immunity to

the full of the

competition)

(Y2.4)

Tabel 2. menunjukkan bahwa hasil uji validitas dari 34butir kuisioner yang diteliti menghasilkan korelasi yang terkecil adalah 0,637dan korelasi terbesar adalah 0,961. Dengan demikian, hasil uji validitas yang dilakukan dengan kuisioner dalam penelitian ini adalah valid karena nilai koefisiennya diatas 0,3 sehingga dapat dilanjutkan ke analisa selanjutnya. Selain itu, seluruh indikator konstruk menunjukkan nilai cronbach alpha > 0,60, maka dapat dijelaskan bahwa seluruh indikator konstruk dalam penelitian ini adalah reliabel dan layak untuk digunakan sebagai instrumen penelitian.

\section{Hasil Evaluasi model pengukuran atau outer model}

\section{Discriminant validity}

Tabel 3.

Hasil Discriminant Validity

\begin{tabular}{|c|c|c|c|c|c|c|c|}
\hline $\begin{array}{c}\text { Variabel } \\
\text { Penelitian }\end{array}$ & AVE & $\begin{array}{l}\text { Akar } \\
\text { AVE }\end{array}$ & $\begin{array}{l}\text { Perceived } \\
\text { Usefulness } \\
\text { (X1) }\end{array}$ & $\begin{array}{c}\text { Perceived } \\
\text { Ease of } \\
\text { Use (X2) } \\
\end{array}$ & $\begin{array}{c}\text { Korelasi } \\
\text { Kualitas } \\
\text { Layanan } \\
\text { (X3) } \\
\end{array}$ & $\begin{array}{c}\text { Kepuasan } \\
\text { Pengguna } \\
\text { (Y1) } \\
\end{array}$ & $\begin{array}{c}\text { Loyalitas } \\
\text { (Y2) }\end{array}$ \\
\hline $\begin{array}{l}\text { Perceived } \\
\text { usefulness } \\
\text { (X1) }\end{array}$ & 0,839 & 0,916 & 1,000 & & & & \\
\hline $\begin{array}{l}\text { Perceived } \\
\text { ease of } \\
\text { use (X2) }\end{array}$ & 0,782 & $\mathbf{0 , 8 8 4}$ & 0,946 & 1,000 & & & \\
\hline $\begin{array}{l}\text { Kualitas } \\
\text { layanan (X3) }\end{array}$ & 0,854 & 0,924 & 0,881 & 0,930 & 1,000 & & \\
\hline $\begin{array}{l}\text { Kepuasan } \\
\text { pengguna (Y1) }\end{array}$ & 0,808 & 0,899 & 0,918 & 0,925 & 0,890 & 1,000 & \\
\hline Loyalitas (Y2) & 0,748 & 0,865 & 0,931 & 0,914 & 0,863 & 0,889 & 1,000 \\
\hline
\end{tabular}

Berdasarkan Tabel 3. tersebut, dapat disimpulkan bahwa nilai akar AVE konstruk perceived usefulness (X1) yaitu 0,916, lebih besar dari korelasi antar 
variabel laten dengan konstruk lainnya. Nilai akar AVE konstruk perceived ease of use (X2) yaitu 0,884, lebih besar dari korelasi antar variabel laten dengan konstruk lainnya. Selanjutnya, nilai akar AVE konstruk kualitas layanan (X3) yaitu 0,924, lebih besar dari korelasi antar variabel laten dengan konstruk lainnya. Nilai akar AVE konstruk kepuasan pengguna (Y1) yaitu 0,899, lebih besar dari korelasi antar variabel laten dengan konstruk lainnya. Nilai akar AVE konstruk loyalitas (Y2) yaitu 0,865, lebih besar dari korelasi antar variabel laten dengan konstruk lainnya. Dengan demikian, semua konstruk dalam model yang diuji memenuhi kriteria discriminant validity.

\section{Convergent Validity}

Tabel 4.

Hasil Pengujian Convergent Validity

\begin{tabular}{|c|c|c|c|}
\hline Variabel & Dimensi & Indikator & $\begin{array}{c}\text { Outer } \\
\text { Loading }\end{array}$ \\
\hline \multirow[t]{5}{*}{$\begin{array}{l}\text { Perceived } \\
\text { Usefulness (X1) }\end{array}$} & - & $\begin{array}{l}\text { Menjadikan pekerjaan lebih mudah } \\
\text { (X1.1) }\end{array}$ & 0,916 \\
\hline & & Bermanfaat (usefull) (X1.2) & 0,905 \\
\hline & & $\begin{array}{l}\text { Menambah produktivitas (increase } \\
\text { productivity) (X1.3) }\end{array}$ & 0,945 \\
\hline & & $\begin{array}{l}\text { Mempertinggi efektivitas (enhance } \\
\text { efectiveness) (X1.4) }\end{array}$ & 0,906 \\
\hline & & $\begin{array}{l}\text { Mengembangkan kinerja pekerjaan } \\
\text { (improve job performance) (X1.5) }\end{array}$ & 0,908 \\
\hline \multirow[t]{5}{*}{$\begin{array}{l}\text { Perceived Ease Of } \\
\text { Use (X2) }\end{array}$} & - & $\begin{array}{l}\text { Adanya kemudahan dipelajari. } \\
\text { (X2.1) }\end{array}$ & 0,889 \\
\hline & & Mudah dipahami dan dimengerti. (X2.2) & 0.909 \\
\hline & & $\begin{array}{l}\text { Mudah untuk berinteraksi. } \\
\text { (X2.3) }\end{array}$ & 0,781 \\
\hline & & $\begin{array}{l}\text { Mudah untuk digunakan/ dioperasikan. } \\
\text { (X2.4) }\end{array}$ & 0,907 \\
\hline & & Keseluruhan mudah digunakan. (X2.5) & 0,928 \\
\hline \multirow{7}{*}{$\begin{array}{l}\text { Kualitas Layanan } \\
\text { (X3) }\end{array}$} & Bukti fisik & Kondisi kendaraan (X3.1.1) & 0,931 \\
\hline & (tangibles) & Perlengkapan keamanan (X3.1.2) & 0,932 \\
\hline & (X3.1) & Identitas driver (X3.1.3) & 0,880 \\
\hline & & Penampilan driver (X3.1.4) & 0,878 \\
\hline & $\begin{array}{l}\text { Keandalan } \\
\text { (reliability) }\end{array}$ & $\begin{array}{l}\text { Keandalan driver manaati peraturan tata } \\
\text { tertib berlalu lintas (X3.2.1) }\end{array}$ & 0,830 \\
\hline & (X3.2) & $\begin{array}{l}\text { Keandalan driver memesan makanan di } \\
\text { berbagai restoran }(\mathrm{X} 3.2 .2)\end{array}$ & 0,885 \\
\hline & & Keandalan driver memberikan tarif yang & 0,911 \\
\hline
\end{tabular}


Kepuasan

Pengguna (Y1)

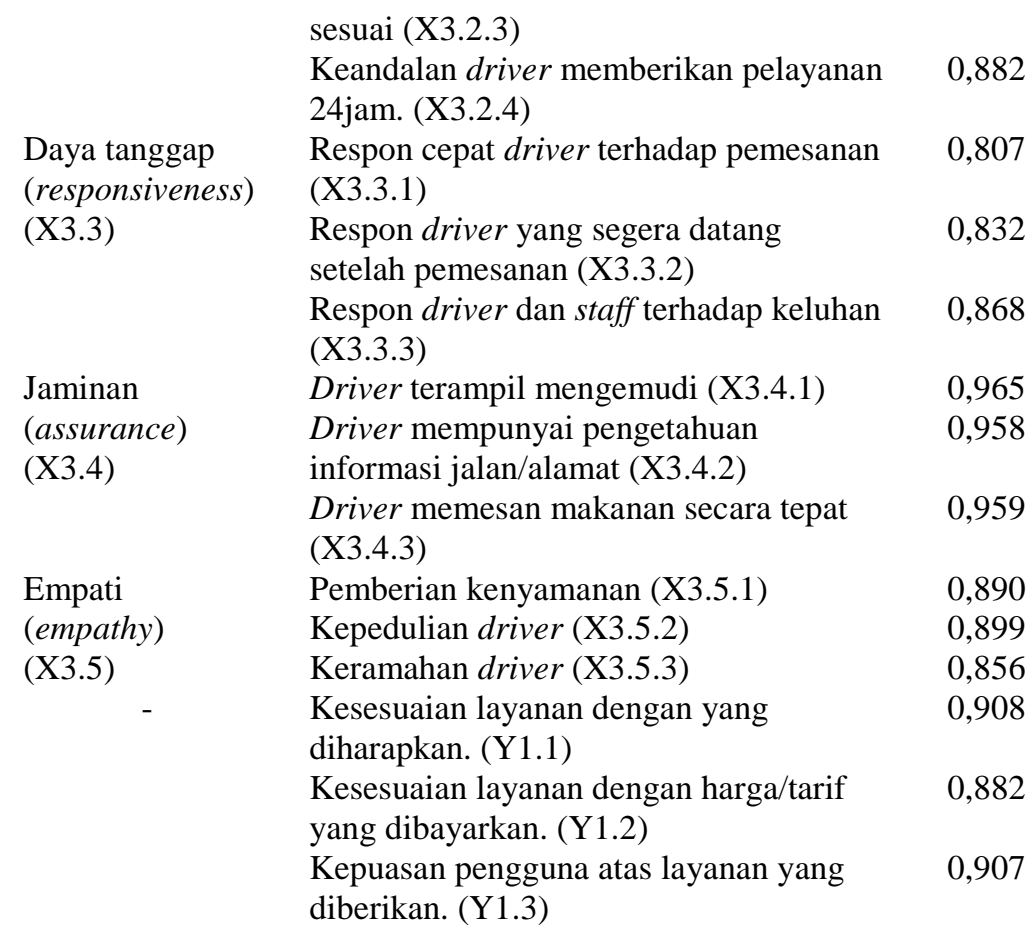

Melakuakan pembelian secara teratur

0,864 (makes regular repeat purchases). (Y2.1)

Melakukan pembelian di semua lini produk atau jasa (puchases across product and service lines). (Y2.2)

Merekomendasikan produk kepada orang lain (refers other). (Y2.3)

Menunjukkan kekebalan oleh daya tarik produk sejenis dari pesaing (demonstrates on immunity to the full of the competition). (Y2.4)

Sumber: Hasil olah data, 2017

Berdasarkan Tabel 4. menunjukkan hasil output telah memenuhi convergent validity karena loading factor berada diatas 0,70 . Dapat dilihat pada tabel di atas pada konstruk perceived usefulness (X1), indikator menambah produktivitas (increase productivity) (X1.3) memiliki nilai outer loadings tertinggi dibandingkan indikator lain yaitu sebesar 0,945 , maka dapat dijelaskan bahwa indikator tersebut dapat merefleksikan konstruk perceived usefulness (X1). Pada konstruk perceived ease of use (X2), indikator keseluruhan mudah 
digunakan. (X2.5) memiliki nilai outer loadings tertinggi dibandingkan indikator lain yaitu sebesar 0,928, maka dapat dijelaskan bahwa indikator tersebut dapat merefleksikan konstruk perceived ease of use (X2). Pada konstruk kualitas layanan (X3), indikator driver terampil mengemudi (X3.4.1) memiliki nilai outer loadings tertinggi dibandingkan indikator lain yaitu sebesar 0,965, maka dapat dijelaskan bahwa indikator tersebut dapat merefleksikan konstruk kualitas layanan (X3). Pada konstruk kepuasan pengguna (Y1), indikator kesesuaian layanan dengan yang diharapkan (Y1.1) memiliki nilai outer loadings tertinggi dibandingkan indikator lain yaitu sebesar 0,908, maka dapat dijelaskan bahwa indikator tersebut dapat merefleksikan konstruk kepuasan pengguna (Y1). Sedangkan pada konstruk loyalitas (Y2), indikator melakukan pembelian di semua lini produk atau jasa (puchases across product and service lines). (Y2.2) memiliki nilai outer loadings tertinggi dibandingkan indikator lain yaitu sebesar 0,933 , maka dapat dijelaskan bahwa indikator tersebut dapat merefleksikan konstruk loyalitas (Y2).

\section{Composite Reliability}

Tabel 5.

Hasil Pengujian Composite Reliability

\begin{tabular}{lccc}
\hline \multicolumn{1}{c}{ Variabel } & Composite Reliability & Cronbachs Alpha & Keterangan \\
\hline $\begin{array}{l}\text { Perceived } \\
\begin{array}{l}\text { Usefulness (X1) } \\
\text { Perceived Ease of }\end{array}\end{array}$ & 0,963 & 0,952 & Reliabel \\
$\begin{array}{l}\text { Use (X2) } \\
\text { Kualitas layanan } \\
\text { (X3) }\end{array}$ & 0,947 & 0,929 & Reliabel \\
$\begin{array}{l}\text { Kepuasan pengguna } \\
(\mathrm{Y} 1)\end{array}$ & 0,967 & 0,957 & Reliabel \\
Loyalitas (Y2) & 0,948 & 0,881 & Reliabel \\
\hline
\end{tabular}


Berdasarkan pada Tabel 5. hasil output composite reliability dan cronbach alpha pada seluruh konstruk diatas 0,70. Dengan demikian, dapat dijelaskan bahwa seluruh konstruk memiliki reliabilitas yang baik.

\section{Evaluasi model struktural atau inner model}

Tabel 6.

\begin{tabular}{cc}
\multicolumn{2}{c}{ Nilai $\boldsymbol{R}$-Square } \\
\hline Variabel & Raribel Terikat \\
\hline Perceived Usefulness (X1) & 0,896 \\
Keuasan Pengguna & 0,879 \\
Loyalitas & 0,815
\end{tabular}

Sumber: Hasil olah data, 2017

Dalam model struktural ini, terdapat tiga variabel terikat, yaitu: perceived usefulness (X1), kepuasan pengguna (Y1), dan loyalitas (Y2). Adapun koefisien determinasi $\left(\mathrm{R}^{2}\right)$ dari masing-masing variable terikat dapat disajikan dalam Tabel 6. diatas.

Untuk mengukur seberapa baik nilai observasi dihasilkan oleh model dan juga estimasi parameternya, maka perlu menghitung $Q$-squaresebagai berikut:

$$
\begin{array}{rll}
\mathrm{Q}^{2} & = & 1-\left(1-\left(\mathrm{R}_{1}\right)^{2}\right)\left(1-\left(\mathrm{R}_{2}\right)^{2}\right)\left(1-\left(\mathrm{R}_{2}\right)^{2}\right) \\
& = & 1-\left(1-(0,896)^{2}\right)\left(1-(0,879)^{2}\right)\left(1-(0,815)^{2}\right) \\
& = & 0,985
\end{array}
$$

Besaran $\mathrm{Q}^{2}$ memiliki nilai dengan rentang $0<\mathrm{Q}^{2}<1$, dimana semakin mendekati 1 berarti model semakin baik.Hasil perhitungan tersebut didapat nilai $\mathrm{Q}^{2}$ adalah sebesar 0,985 , sehingga dapat disimpulkan bahwa model memiliki predictive relevanceyang sangat baik $\left(Q^{2}=0,985>0\right)$.

\section{Hasil Pengujian Hipotesis}

Partial Least Square(PLS) 
Tabel 7.

Hasil Output PLS (Path Coefficient)

\begin{tabular}{|c|c|c|c|c|}
\hline Konstruk & $\begin{array}{c}\text { Koefisien } \\
\text { Korelasi }\end{array}$ & t Statistics & p Values & Keterangan \\
\hline $\begin{array}{l}\text { Perceived usefulness }(\mathrm{X} 1) \rightarrow \\
\text { Kepuasan pengguna }(\mathrm{Y} 1)\end{array}$ & 0,401 & 4,773 & 0,000 & Signifikan \\
\hline $\begin{array}{l}\text { Perceived ease of use }(\mathrm{X} 2) \rightarrow \\
\text { Kepuasan pengguna }(\mathrm{Y} 1)\end{array}$ & 0,344 & 2,102 & 0,037 & Signifikan \\
\hline $\begin{array}{l}\text { Perceived ease of use (X2) } \rightarrow \\
\text { Perceived usefulness (X1) }\end{array}$ & 0,946 & 111,595 & 0,000 & Signifikan \\
\hline $\begin{array}{l}\text { Kualitas layanan }(\mathrm{X} 3) \rightarrow \\
\text { Kepuasan pengguna }(\mathrm{Y} 1)\end{array}$ & 0,944 & 68,235 & 0,077 & Tidak Signifikan \\
\hline $\begin{array}{l}\text { Kualitas layanan }(\mathrm{X} 3) \rightarrow \\
\text { Loyalitas } \\
\text { (Y2) }\end{array}$ & 0,861 & 38,783 & 0,000 & Signifikan \\
\hline $\begin{array}{l}\text { Kepuasan pengguna (Y1) } \rightarrow \\
\text { Loyalitas (Y2) }\end{array}$ & 0,949 & 100,354 & 0,000 & Signifikan \\
\hline
\end{tabular}

Sumber: Hasil olah data, 2017

Berdasarkan Tabel 7. dapat disimpulkan bahwa perceived usefulness berpengaruh langsung terhadap kepuasan pengguna dengan koefisien sebesar 0,401 dan signifikan pada 5 persen (nilai $\mathrm{t}$ hitung $>\mathrm{t}$ tabel 1,96), perceived ease of use berpengaruh langsung terhadap kepuasan pengguna dengan koefisien sebesar 0,344 dan signifikan pada 5 persen (nilai thitung $>\mathrm{t}$ tabel 1,96), perceived ease of use berpengaruh langsung terhadap perceived usefulness dengan koefisien sebesar 0,946 dan signifikan pada 5 persen (nilai t hitung > t tabel 1,96), kualitas layanan tidak berpengaruh langsung terhadap kepuasan pengguna dengan koefisien 0,216 dan signifikan pada 5 persen (nilai t hitung $>\mathrm{t}$ tabel 1,96), kualitas layanan berpengaruh langsung terhadap loyalitas dengan koefisien sebesar 0,343 dan signifikan pada 5 persen (nilai t hitung > t tabel 1,96), kepuasan pengguna berpengaruh langsung terhadap loyalitas dengan koefisien sebesar 0,584 dan signifikan pada 5 persen (nilai t hitung > t tabel 1,96).

\section{Pembahasan}




\section{Pengaruh Perceived Usefulness Terhadap Kepuasan Pelanggan}

Hasil estimasi model struktural seperti disajikan pada Tabel 7. analisis menunjukkan bahwa pengujian hipotesis pada perceived usefulnessterhadap kepuasan pengguna menghasilkan nilai koefisien korelasi sebesar 0,401 , nilai $\mathrm{t}$ statistik sebesar 4,773, dan $\mathrm{p}$ values sebesar $0,000 \quad(<0,05)$. Hal tersebut menunjukkan bahwa perceived usefulnessberpengaruh positif dan signifikan terhadap kepuasan pengguna. Dengan demikian H1 diterima. Hal ini memiliki makna bahwa semakin baik aplikasi GO-JEK memberikan manfaat yang dirasakan oleh penggunanya, maka semakin tinggi kepuasan yang dirasakan oleh penggunanya.

Hasil ini sesuai denganbeberapa penelitian terdahulu yakni penelitian yang dilakukan oleh seperti Amin et al. (2014) yang menyatakan bahwa perceived usefulness berpengaruh signifikan terhadap pengguna website mobile di Malaysia. Hal ini memperkuat aturan nilai dan kegunaan teknologi dalam mendapatkan kepuasan dan loyalitas pelanggan.

\section{Pengaruh Perceived Ease of Use Terhadap Kepuasan Pengguna}

Hasilestimasi model struktural seperti disajikan pada Tabel 7. analisis menunjukkan bahwa pengujian hipotesis pada perceived ease of use terhadap kepuasan pengguna menghasilkan nilai koefisien korelasi sebesar 0,344 , nilai $t$ statistik sebesar 2,102, dan $\mathrm{p}$ values sebesar $0,037 \quad(<0,05)$. Hal tersebut menunjukkan bahwa perceived ease of use berpengaruh positif dan signifikan terhadap kepuasan pengguna. Dengan demikian H2 diterima. Hal ini memiliki 
makna bahwa semakin baik teknologi aplikasi GO-JEK memberikan kemudahan yang dirasakan oleh penggunanya, maka semakin tinggi kepuasan yang dirasakan oleh penggunanya.

Hasil ini sesuai dengan penelitian yang dilakukan Tananjaya (2012) yang menyatakan bahwa proses implementasi software akuntansi pada biro perjalanan wisata di Surabaya tidak terlepas dari peran perceived easy of use yang juga mempengaruhi keberhasilan proses implementasi software akuntansi yang berkaitan dengan kepuasan penggunanya.

\section{Pengaruh Perceived Ease of Use Terhadap Perceived Usefulness}

Hasil estimasi model struktural seperti disajikan pada Tabel 7. analisis menunjukkan bahwa pengujian hipotesis pada perceived ease of use terhadap perceived usefulness menghasilkan nilai koefisien korelasi sebesar 0,946 , nilai $\mathrm{t}$ statistik sebesar 111,595, dan $\mathrm{p}$ values sebesar $0,00(<0,05)$. Hal tersebut menunjukkan bahwa perceived ease of use berpengaruh positif dan signifikan terhadapperceived usefulness. Dengan demikian H3 diterima. Hal ini memiliki makna bahwa semakin mudah cara mengakses teknologi aplikasi GO-JEK, maka akan semakin memberikan manfaat yang lebih besar bagi penggunanya.

Hasil ini sesuai dengan teori Technology Acceptance Model (TAM) yang disusun oleh Davis (1989) yang menyatakan bahwa sikap pemakai sistem informasi ditentukan oleh kegunaan yang dirasakan (perceived usefulness) dan kemudahan penggunaan yang dirasakan (perceived ease of use). Pemakai akan 
merasakan manfaat yang lebih besar jika merasakan kemudahan dalam menggunakan sistem informasi tersebut.

\section{Pengaruh Kualitas Layanan Terhadap Kepuasan Pengguna}

Hasil estimasi model struktural seperti disajikan pada Tabel 7. analisis menunjukkan bahwa pengujian hipotesis pada kualitas layanan terhadap kepuasan pengguna menghasilkan nilai koefisien korelasi sebesar 0,216, nilai t statistik sebesar 1,781, dan $\mathrm{p}$ values sebesar $0,077(>0,05)$. Hal tersebut menunjukkan bahwa kualitas layanan tidak berpengaruh positif signifikan terhadap kepuasan pengguna. Dengan demikian, maka $\mathrm{H} 4$ ditolak. Hal ini menunjukkan bahwa layanan yang diberikan oleh para driver GO-JEK belum maksimal, sehinngga penggunanya merasa kurang puas dengan layanan yang diberikan.

Hal ini menunjukkan bahwa layanan yang diberikan oleh para driver GOJEK belum maksimal, sehinngga penggunanya merasa kurang puas dengan layanan yang diberikan. Hasil ini mengindikasikan dan memberikan sebuah peringatan agar para driver GO-JEK memberikan kualitas layanan yang lebih baik lagi agar pengguna aplikasi merasa lebih puas terhadap pelayanan yang diberikan.

\section{Pengaruh Kualitas Layanan Terhadap Loyalitas}

Hasilestimasi model struktural seperti disajikan pada Tabel 7. analisis menunjukkan bahwa pengujian hipotesis pada kualitas layanan terhadap loyalitas menghasilkan nilai koefisien korelasi sebesar 0,343, nilai t statistik sebesar 4,295, dan $\mathrm{p}$ values sebesar $0,000(<0,05)$. Hal tersebut menunjukkan bahwa kualitas 
layanan berpengaruh positif signifikan terhadap loyalitas. Dengan demikian, maka H5 diterima. Hal ini menunjukkan bahwa layanan yang diberikan oleh para driver GO-JEK akan membuat penggunanya akan tetap menggunakan layanan aplikasi GO-JEK kembali apabila membutuhkannya, walaupun kualitas layanannya sudah ataupun belum memberikan kepuasan.

Hal ini sesuai dengan penelitian terdahulu oleh Minh dan Nguyen (2016) menunjukkan kualitas layanan secara signifikan dan positif terkait dengan loyalitas pelanggan yang menjadikannya salah satu sumber untuk meningkatkan loyalitas pelanggan.

\section{Pengaruh Kepuasan Pengguna Terhadap Loyalitas}

Hasilestimasi model struktural seperti disajikan pada Tabel 7. analisis menunjukkan bahwa pengujian hipotesis pada kepuasan pengguna terhadap loyalitas menghasilkan nilai koefisien korelasi sebesar 0,584 , nilai t statistik sebesar 7,526, dan $\mathrm{p}$ values sebesar $0,000(<0,05)$. Hal tersebut menunjukkan bahwa kepuasan pengguna berpengaruh positif signifikan terhadap loyalitas. Dengan demikian, maka H6 diterima. Hal ini menunjukkan bahwa kepuasan yang dirasakan pengguna oleh layanan aplikasi GO-JEK akan membuat penggunanya tetap menggunakan aplikasi GO-JEK baik dari fitur GO-RIDE, GO-FOOD dan fitur-fitur lainnnya yang disediakan oleh aplikasi GO-JEK.

Hasil penelitian ini sesuai dengan penelitian terdahulu yang dilakukan oleh Koduah dan Augustine (2016) yang mengungkapkan adanya hubungan positif 
yang signifikan antara kepuasan pelanggan dan loyalitas pelanggan pelanggan di sektor perbankan Ghana.

\section{SIMPULAN DAN SARAN}

Berdasarkan hasil pembahasan penelitian yang telah dilakukan, maka dapat disimpulkan bahwa:

1) Perceived usefulness berpengaruh positif dan signifikan terhadap kepuasan pengguna, artinya semakin baik perceived usefulness pada aplikasi layanan GO-JEK, maka semakin tinggi pula kepuasan penggunanya.

2) Perceived ease of use berpengaruh positif dan signifikan terhadap kepuasan pengguna, artinya semakin baikperceived ease of use pada aplikasi layanan GO-JEK, maka semakin tinggi pula kepuasan penggunanya.

3) Perceived ease of use berpengaruh positif dan signifikan terhadap perceived usefulness, artinya semakin tinggi perceived ease of use dari layanan aplikasi GO-JEK, maka semakin tinggi pula kepuasan penggunanya.

4) Kualitas layanan berpengaruh positif tetapi tidak signifikan terhadap kepuasan pengguna, artinya kualitas layanan yang diberikan driver GOJEK tidak menjadi tolak ukur bagi pengguna untuk merasa puas pada layanan GO-JEK. 
5) Kualitas layanan berpengaruh positif signifikan terhadap loyalitas, artinya semakin tinggi kualitas layanan yang diberikan driver GO-JEK maka semakin tinggi pula loyalitas pengguna aplikasi layanan GO-JEK.

6) Kepuasan pengguna berpengaruh positif signifikan terhadap loyalitas, artinya semakin tinggi kepuasan pengguna maka semakin tinggi pula loyalitas pada aplikasi layanan GO-JEK.

\section{Saran}

\section{Bagi Praktisi}

Pihak manajemen dari GO-JEK perlu berfokus dengan kualitas layanan dari driver-driver GO-JEK, karena selain faktor pada teknologinya, faktor kualitas layanan ini pun merupakan faktor penting untuk memberikan kepuasan pada penggunanya. Terdapat banyak driver yang bergabung pada perusahaan GO-JEK, yang terkadang ada yang memberikan kualitas layanan yang baik atau pun kurang baik. Apabila penggunanya mendapat kualitas layanan dari driver yang kurang baik, maka pengguna tersebut akan merasa tidak puas. Pihak manajemen sebaiknya harus tetap fokus mengawasi kualitas yang diberikan oleh para driver, dengan begitu kepuasan dari penggunanya akan tetap terjaga.

\section{Bagi Akademisi}

1) Penelitian di masa mendatang perlu mempertimbangkan untuk menggunakan konstruk lain seperti persepsi nilai yang dapat menjadi prediktor kepuasan pengguna. Selain itu penelitian berikutnya juga bisa menggunakan karakteristik demografi misalnya usia dalam membedakan tingkat penerimaan kemanfaatan dan kemudahan sebuah teknologi baru. 
2) Penelitian dimasa mendatang perlu memperkaya temuan studi empiris dengan mengkaji teknologi aplikasi layanan jasa transportasi lainnya maupun jasa dalam kategori yang berbeda.

\section{REFERENSI}

Agyapong, Gloria K. Q. 2011. The Effect of Service Quality on Customer Satisfaction in the Utility Industry - A Case of Vodafone Ghana. International Journal of Business, Vol. 6 No. 5. pp. 203- 210.

Ariani, W.D. 2014. Manajemen Operasi Jasa. Yogyakarta: Graha Ilmu.

Alsemgeest, L. 2014. Satisfaction Towards Management as a Means to Influence Customer Satisfaction - The Case of a South African Farmer-Controlled Business. Journal of Co-operative Studies, Vol.7 No:3, pp. 34-44.

Amin M., Sajad R., \& Maryam A. 2014. User satisfaction with mobile websites: the impact of perceived usefulness (PU), perceived ease of use (PEOU) and trust. Nankai Business Review International Vol. 5 No. 3, 2014 pp. 258274.

Arthur, Y.D., Francois, S., Evans, K.M., \& Walter, B. 2016. The Impact of Service Quality on Customer Satisfaction in Obuasi Electricity Company of Ghana (ECG) - The Customer Perspective. International Journal of Contemporary Applied Sciences. Vol.3 No.3, pp: 247-256.

Attuquayefio, S. N., \& Hillar, A. 2014. Using the UTAUT model to analyze students' ICT adoption. International Journal of Education and Development using Information and Communication Technology (IJEDICT), Vol. 10, Issue 3, pp. 75-86.

Budiman, F. \& Fefri I.A. 2013. Pendekatan Technology Acceptance Model dalam Kesuksesan Implementasi Sistem Informasi Manajemen Daerah. Jurnal WRA, Vol. 1 No, 1. pp. 35-42.

Cho, Yoon C. 2015. Exploring Factors That Affect Usefulness, Ease Of Use, Trust, And Purchase Intention In The Online Environment. International Journal of Management \& Information Systems Vol. 19 No. 1. pp. 234-241.

Dalbouh, H.M. 2013. A Questionnaire Approach Based On The Technology Acceptance Model For Mobile Tracking On Patient Progress Applications. Journal of Computer Science 9 (6) pp. 763-770.

Davis, F. D. 1989. Perceived Usefulness, Perceived Easy of Use, and User Acceptance of Information Technology. International Journal Management Machine Studies. Vol. 13. No. 5. Pp. 319-339. 
Dominici, G. \& Guzzo, R., 2010. Customer Satisfaction in the Hotel Industry: A Case Study from Sicily. International Journal of Marketing Studies, 2(2), pp. 3-12.

Fathima, N., David, S., \& Margaret, Ross. 2015. Expanding The Technology Acceptance Model (TAM) to Examine Faculty Use of Learning Management Systems (LMSs) In Higher Education Institutions. MERLOT Journal of Online Learning and Teaching Vol. 11, No. 2. pp. 87-91.

Ferdinand, A. 2002. Structural Equation Modeling Dalam Penelitian Manajemen. Semarang: BP UNDIP.

Fuad., \& Fefri, I.A. 2013. Pendekatan Technology Acceptance Model dalam Kesuksesan Implementasi Sistem Informasi Manajemen Daerah. Jurnal WRA, Vol. 1 No. 1. pp. 113-118.

Gaith, W.A. 2015. Applying The Technology Acceptance Model to Understand Social Networking Sites (Sns) Usage: Impact Of Perceived Social Capital. International Journal of Computer Science \& Information Technology (IJCSIT) Vol 7, No 4. pp. 24-27.

George, A., \& Kumar, G. S. G. 2013. Antecedents of customer satisfaction in internet banking: Technology Acceptance Model Redefined. Global Business Review, Vol.14 No.4, pp. 627-638.

Ghozali, I. 2014. Aplikasi Analisis Multivariate dengan Program SPSS. Semarang: Badan Penerbit Universitas Diponegoro.

Hasugian, J.T.M. 2015. Pengaruh Brand Image Dan Brand Trust Terhadap Brand Loyalty Telkomsel; Survey Terhadap Pelanggan Telkomsel di Grapari Samarinda. e-Journal Ilmu Administrasi Bisnis, Vol. 3. No.4. pp. 923-937.

https://play.google.com/store/apps/details?id=com.gojek.app\&hl=en

Irfan, M., Shamsudin, M.F., \& Noor, U.H. 2016. How Important Is Customer Satisfaction? Quantitative Evidence from Mobile Telecommunication Market. International Journal of Business and Management; Vol. 11, No. 6. pp. 65-71.

Juniwati. 2014. Influence of Perceived Usefulness, Ease of Use, Risk on Attitude and Intention to Shop Online. European Journal of Business and Management. Vol.6. pp.134-138.

Kazi, O.S. 2011.Interrelations between Service Quality Attributes, Customer Satisfaction and Customer Loyalty in the Retail Banking Sector in Bangladesh. International Journal of Business and Management Vol. 6, No. 3.pp.12-36. 
Kim Y., \& Hyung S.L. 2014. Quality, Perceived Usefulness, User Satisfaction, and Intention to Use: An Empirical Study of Ubiquitous Personal Robot Service. Asian Social Science. Vol.10. No. 11. pp.1-16

Koduah, E.Y.T., \& Augustine, Y.D.F. 2016. Relationship between Customer Satisfaction and Customer Loyalty in the Retail Banking Sector of Ghana. International Journal of Business and Management. Vol.10. pp.34-46.

Kurniati, D., Suharyono., \& Andriani, K. 2014. Pengaruh Citra Merek Dan Kualitas Produk Terhadap Kepuasan Dan Loyalitas Pelanggan (Studi Pada Pelanggan Kfc Cabang Kawi Malang). Jurnal Administrasi Bisnis (JAB)|Vol. 14 No. 2. pp.13-23.

Liebana-Cabanillas, F., Muñoz-Leiva, F., \& Rejón-Guardia, F. (2013). The determinants of satisfaction with e-banking. Industrial Management and Data Systems, Vol. 113. No.5, pp. 750-767.

Lovelock, C. H., \& Lauren K, W. 2007. Manajemen Pemasaran Jasa. Jakarta: Indeks

Magatef, S. G., \& Elham F, T. 2015. The Impact of Customer Loyalty Programs on Customer Retention. International Journal of Business and Social Science Vol. 6, No. 8(1); 15-22

Mayantoko, N. 2013. Pengaruh Experiential Marketing dan Kualitas Pelayanan terhadap Kepuasan Pelanggan (Hoka-Hoka Bento Cabang Mall Karawang). Journal Manajemen Vol. 11 No. 1. pp.1-14.

Miller, R.E., \& Brooks, N.J. 2010. Class Service Quality: Moving Beyond SERVQUAL. Paper presented at Information Systems Educators Conference, Nashville Tennessee, USA.

Minh, N.V., \& Nguyen, H.H. 2016. The Relationship between Service Quality, Customer Satisfaction and Customer Loyalty: An Investigation in Vietnamese Retail Banking Sector. Journal of Competitiveness Vol. 8, Issue 2, pp. $103-116$.

Munari, L., Lelasi, F., \& Bajetta, L. 2013. Customer Satisfaction Management in Italian Banks. Qualitative Research in Financial Markets, Vol. 5. No.2, pp.139-160.

Muntianah, S.T., Endang, S.A., \& Devi, F.A. 2012. Pengaruh Minat Perilaku Terhadap Actual Use Teknologi Acceptance Model (TAM): Studi Kasus Pada Kegiatan Belajar Mahasiswa Fakultas Ilmu Administrasi Universitas Brawijaya Malang). Profit Vol. 6 No.1. pp.12-23.

Nariswari, R., \& Iriawan, N. 2012. Analisis Pengaruh Kualitas pelayanan, Kepuasan Nasabah, dan Kepercayaan terhadap Loyalitas Nasabah Flexi 
Mobile Broadband di Wilayah Surabaya dengan Pendekatan SEM Bayesian. Jurnal Sains dan Seni ITS, Vol.1.No.1. pp.1-18.

Quyet, Tran V., Nguyen, Q. V., \& Taikoo, C. 2015. Service Quality Effects on Customer Satisfaction in Banking Industry. International Journal of $u$ - and e-Service, Science and Technology Vol.8, No. 8, pp.199-206.

Ratnaningrum, L.P.R.A. 2013. Aplikasi Model TAM Terhadap Pengguna Layanan Internet Banking di Kota Denpasar (tesis). Denpasar: Universitas Udayana.

Ravichandran, K., Mani B T., Kumar S A., \& S Prabhakaran. 2010. Influence of Service Quality on Customer Satisfaction Application of Servqual Model. International Journal of Business and Management Vol. 5, No. 4.

Santoso, S. 2007. Riset Pemasaran (Konsep dan Aplikasi dalam SPSS). Jakarta: PT Alex Media Komputindo.

Sembiring, I.J., Suharyono., \& Andriani K. 2014. Pengaruh Kualitas Produk Dan Kualitas Pelayanan Terhadap Kepuasan Pelanggan Dalam Membentuk Loyalitas Pelanggan (Studi pada Pelanggan McDonald's MT.Haryono Malang). Jurnal Administrasi Bisnis (JAB)|Vol. 15 No.1. pp.23-32.

Singh, R., \& Khan I. 2012. An Approach to Increase Customer Retention and Loyalty in B2C World. International Journal of Scientific and Research Publications, Volume2, Issue 6. pp. 46-58.

Söderlund, M., \& Rosengren, S. 2010. The happy versus unhappy service worker in the service. Encounter: Assessing the impact on customer satisfaction. Journal of Retailing and ConsumerServices Vol.17. pp.161-169.

Tananjaya, V.A. 2012. Kualitas Sistem Informasi, Kualitas Informasi, Dan Perceived Usefulness Terhadap Keberhasilan Implementasi Software Akuntansi. Berkala Ilmiah Mahasiswa Akuntansi, Vol.1. No.3. pp.1-16.

Tang, Kai Y., \& Chun, H.H. 2016. The Literature Development of Technology Acceptance Model. Tjiptono, Fandy. 2012. Service Management Mewujudkan Layanan Prima. Yogyakarta: CV Andi Offset International Journal of Conceptions on Management and Social Sciences Vol. 4, Issue. 1. pp. 31-43.

Writz, Bernd, W., \& Vincent Göttel. 2016. Technology Acceptance In Social Media: Review, Synthesis And Directions For Future Empirical Research. Journal of Electronic Commerce Research, Vol. 17, No. 2, pp.167-183. 